\title{
Decontamination of Powdery Foods Using an Intense Pulsed Light (IPL) Device for Practical Application
}

\author{
Hee-Jeong Hwang ${ }^{1}$, So-Yoon Yee $^{2}$ and Myong-Soo Chung ${ }^{2, *(D)}$ \\ 1 Research Institute of Biotechnology \& Medical Converged Sciences, Dongguk University, \\ Goyang 10326, Korea; piatop@hanmail.net \\ 2 Department of Food Science and Engineering, Ewha Womans University, Seoul 03760, Korea; \\ roseyee@naver.com \\ * Correspondence: mschung@ewha.ac.kr; Tel./Fax: +82-2-32774508
}

Citation: Hwang, H.-J.; Yee, S.-Y.; Chung, M.-S. Decontamination of Powdery Foods Using an Intense Pulsed Light (IPL) Device for Practical Application. Appl. Sci. 2021, 11, 1518. https://doi.org/10.3390/ app11041518

Academic Editor: Monica Gallo Received: 30 December 2020

Accepted: 2 February 2021

Published: 8 February 2021

Publisher's Note: MDPI stays neutral with regard to jurisdictional claims in published maps and institutional affiliations.

Copyright: (c) 2021 by the authors. Licensee MDPI, Basel, Switzerland. This article is an open access article distributed under the terms and conditions of the Creative Commons Attribution (CC BY) license (https:// creativecommons.org/licenses/by/ $4.0 /)$.

\begin{abstract}
Controlling microbial problems when processing seeds and powdered foods is difficult due to their low water activity, irregular surfaces, and opaqueness. Moreover, existing thermal processing can readily cause various undesirable changes in sensory properties. Intense pulsed light (IPL) can be effective in nonthermal processing, and so two xenon lamps were attached to the sides of a self-designed cyclone type of pilot-scale IPL device. Each lamp was connected to its own power supply, and the following treatment conditions were applied to four sample types: lamp DC voltage of $1800-4200 \mathrm{~V}$, pulse width of $0.5-1.0 \mathrm{~ms}$, frequency of $2 \mathrm{~Hz}$, and treatment time of $1-5 \mathrm{~min}$. This device achieved reductions of $0.45,0.66$, and $0.88 \log \mathrm{CFU} / \mathrm{mL}$ for ground black pepper, red pepper, and embryo buds of rice, respectively, under a total energy fluence of $12.31 \mathrm{~J} / \mathrm{cm}^{2}$. Meanwhile, $>3-\log$ reductions were achieved for sesame seed samples under a total energy fluence of $11.26 \mathrm{~J} / \mathrm{cm}^{2}$. In addition, analyses of color changes, water activity, and moisture content revealed no significant differences between the control and IPL-treated samples. These findings indicate that IPL treatment may be considered a feasible sterilization method for seeds and powdered foods.
\end{abstract}

Keywords: intense pulsed light (IPL); cyclone; pilot scale; seeds; powdered foods

\section{Introduction}

Black pepper and red pepper are spices that are commonly added to enhance the flavor, taste, and color of food dishes. Black pepper is also used for pharmaceutical and medicinal purposes to treat different kinds of diseases, such as indigestion, obesity, vertigo, asthma, sinusitis, and even fever, due to its antioxidant, antimicrobial, and nutritional properties [1] Sesame seeds (Sesamum indicum) have been a popular ingredient in Asian, African, and Middle Eastern countries, with Korean food in particular using sesame seeds and oil in many dishes due to its pleasant flavor and taste. The embryo bud of rice constitutes a small portion of the actual rice grain but contains more than $60 \%$ of the nutrients and most of the genetic information required for seed germination [2]. Packaged embryo buds of rice are now widely available in the marketplace, and demand for rice embryos is increasing. People usually mix rice embryos with white and brown rice for health reasons.

Many different types of microorganisms can contaminate seeds and powdered products, including Bacillus spp., Salmonella spp., Escherichia coli, Clostridium perfringens, and aflatoxigenic Aspergillus spp. [3]. It is very important to inactivate microorganisms in seed and powdered foods, as even small amounts of microorganisms can cause food spoilage and foodborne diseases [4-6].

Seeds and powdered food products have a very low moisture content and water activity due to the dry conditions during processing, distribution, and storage, which makes contaminating microorganisms much more resistant to external stimuli such as heat and light compared to the same microorganisms in foodstuffs exhibiting much higher levels of moisture and water activity. For these reasons, thermal sterilization processes (e.g., dry heat, 
steam, microwaves, joule-effect treatment, and fumigation), irradiation, and vacuum gassing are often used in the food industry for effective microbial inactivation in food products [7]. However, thermal methods induce many undesirable changes such as color modification, flavor change, nutrient destruction, and loss of essential oils [8]. These thermal processing methods can markedly reduce the levels of pathogens and nonpathogenic microorganisms in food products, but with these resulting in degraded food quality, it is necessary to consider other methods of inactivation, and the nonthermal sterilization method can be an alternative. Nonthermal processing meets the consumer demand for fresh and minimally processed foods but is also energy-efficient and cost-effective [9].

An intense pulsed light (IPL) system aims to reduce the number of surface microorganisms by applying high-intensity light over a broad wavelength range within a short time. It is an effective and rapid method that represents a feasible alternative to thermal sterilization. In terms of its food-industry applications, an IPL system can significantly extend the shelf life of a foodstuff while maintaining its quality. Some previous studies have specifically applied IPL to foodstuffs. Among them, Agüero et al. [10] evaluated changes in the quality characteristics of inoculated spinach immediately after IPL exposure and after storage. After IPL treatment at $8-120 \mathrm{~kJ} / \mathrm{m}^{2}$, the inoculum on the surface of the spinach showed 1.72- to 2.60-log reductions, and the gas composition, color changes, and antioxidant potential all indicated an improved quality [11-13].

The objective of the present study was to develop a sterilization device for the mass production of seeds and powdered foods using IPL that would have a greater effect on reducing natural microorganisms existing on sample surfaces. Relevant previous studies of IPL have mainly used microorganisms on an artificial growth medium or in inoculated liquid food samples. In contrast, this study targeted the direct treatment of noninoculated microorganisms on seeds and powdered foods. In addition, a pilot-scale IPL device (rather than a laboratory-scale one) that can handle large sample quantities was devised. Moreover, not only the changes in the numbers of microorganisms but also the changes in the physical properties of the samples that are strongly related to sensory characteristics were measured.

\section{Materials and Methods}

\subsection{Sample Preparation}

Black pepper originating from Malaysia was purchased at a local market. The purchased peppercorn was ground using a mixer (Hood Mixer FM-681, Hanil Electric, Inchen, Korea). Red pepper (South Korea), embryo buds of rice (South Korea), and whole sesame seeds (China) were also purchased from the market in unroasted and ground form. The initial contamination levels for black pepper, red pepper, sesame seeds, and embryo buds of rice were $6,5,3$, and $4 \log \mathrm{CFU} / \mathrm{g}$, respectively, and all four samples had $80-90 \%$ of bacteria and $10-20 \%$ of yeast $/ \mathrm{mold}$. In order to maintain the quality of the sample, all samples were divided into black plastic bags containing $1 \mathrm{~kg}$ each and kept refrigerated, and the storage period of samples stored at this temperature did not exceed 3 weeks. During the 3 weeks, there were no changes in moisture content or color of the samples. Before the IPL treatment, $150 \mathrm{~g}$ of each sample was weighed in a sterilized bag (Cat. No. B01196, Whirl-Pak, Nasco, Fort Atkinson, WI, USA) and left at room temperature for at least $2 \mathrm{~h}$.

\subsection{IPL Device}

A pilot-scale IPL device designed for the effective inactivation of microorganisms in powdered foods is shown in Figure 1.

This device comprises three main parts: two power supplies and their chilling systems, two lamps, and a treatment chamber. The power supply includes a controller and capacitor bank and was developed using an external triggering method in which a high voltage is applied to the lamp in short time intervals. The pulse-lamp capacitor is located under the controller and is the most important device for storing energy. The main AC voltage is first boosted before being rectified into DC. The trigger output is $20-30 \mathrm{kV}$, the pulse width is $0.5-1.0 \mathrm{~ms}$, and the output DC voltage can range from 1800 to $5000 \mathrm{~V}$. Each 
power supply is connected to a xenon lamp (type CP3939, XAP series, Heraeus Noblelight, Cambridge, U.K.). Each lamp is surrounded by two quartz tubes through which coolant maintained at $21-23{ }^{\circ} \mathrm{C}$ by the chilling system flows to prevent the lamp from overheating. The components fixing the lamp at each end to prevent the leakage of cooling water were changed from acrylic to Teflon (which has higher heat resistance) in order to enhance the heat stability.

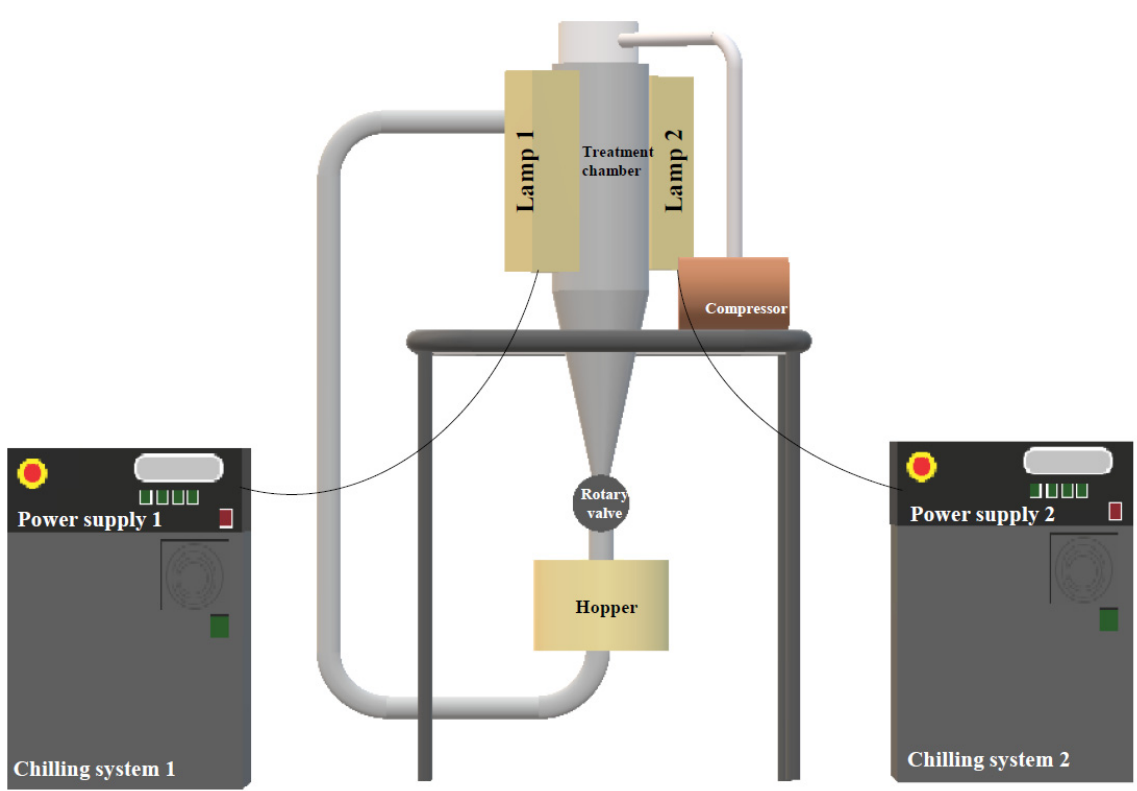

Figure 1. Schematic diagram of intense pulsed light (IPL) treatment system.

The entire size of the stainless-steel treatment chamber for the sterilization of seeds and powdered foods is $1000 \mathrm{~mm}, 2360 \mathrm{~mm}$, and $800 \mathrm{~mm}$ in width, height, and depth, respectively. The powder rotates and drops in a cyclonic flow by the compressor, and the rotary valve helps constant amounts of the sample to drop into the hopper. The flow velocity and residence time of the sample is adjusted by changing the rotation speed of the rotary valve and the intensity of the blower. The rotation speed of the rotary valve can be controlled by adjusting the rpm from 5 to 25 , and the air velocity at each rpm was measured using an airflow anemometer (GM8901, BENETECH, Aurora, IL, USA). It was confirmed that it appeared from $2.5 \mathrm{~m} / \mathrm{s}$ to $12.7 \mathrm{~m} / \mathrm{s}$.

\subsection{Treatment Conditions}

To apply IPL treatment to the sesame seeds, ground black pepper, red pepper, and embryo buds of rice, the DC voltages (1800, 2600, 3400, and $4200 \mathrm{~V})$ and treatment times $(60,120,180,240$, and $300 \mathrm{~s})$ were set in the controller. The total energy fluence of light emitted by the CP3939 lamp was $1.28-12.31 \mathrm{~J} / \mathrm{cm}^{2}$, and the spectral distribution of IPL was measured using a spectroradiometer (ILT950, International Light Technologies, Peabody, MA, USA) (Figure 2).

The temperature change inside the treatment chamber for a supposedly nonthermal treatment was determined by measuring the temperature of the air flowing inside the chamber using a thermometer (TES-1312A, TES Electrical Electronic, Taipei, Taiwan) at the outlet of the pipe after the air blown by the blower circulated inside the device, and it was found that the air temperature increased by only $3.5^{\circ} \mathrm{C}$ under the maximum treatment condition (4200 V for $300 \mathrm{~s}$ ), while that of the sample increased by approximately $3.1^{\circ} \mathrm{C}$. The speed of the rotary valve for all samples was fixed at $20 \mathrm{rpm}$. The sample velocity (as set by the blower intensity) was set at $10.5 \mathrm{~m} / \mathrm{s}$ for ground black pepper, ground red pepper, and embryo buds of rice, and $7.4 \mathrm{~m} / \mathrm{s}$ for sesame seeds, based on consideration of the relative rigidities of the samples. The control sample was subjected to the same 
conditions as the treatment group, with the exception of not being exposed to the light from the lamps. Three measurements were taken for each sample.

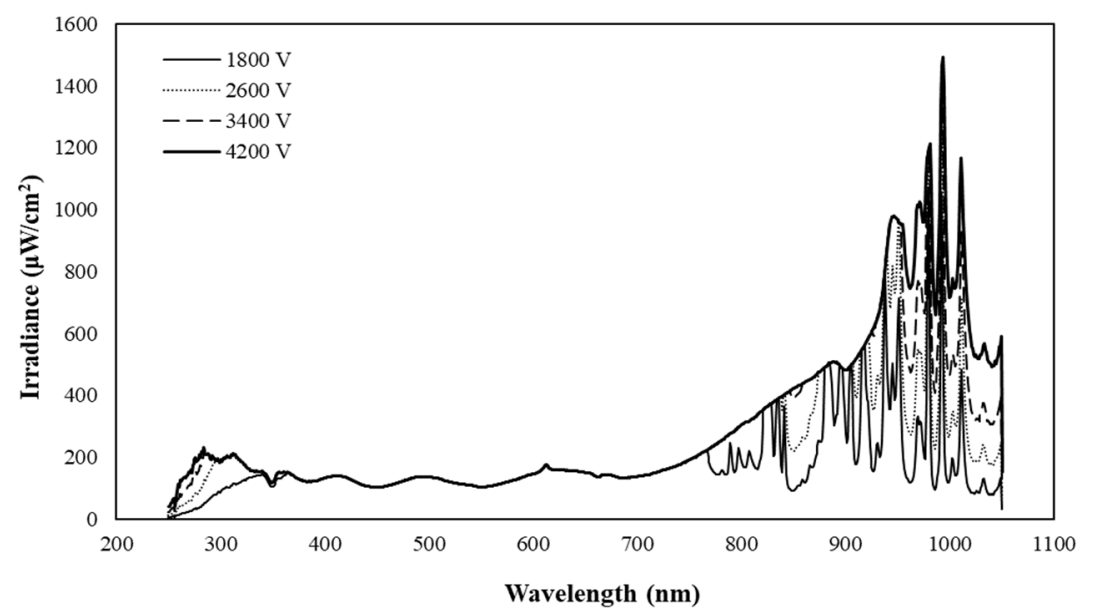

Figure 2. Spectral distribution of IPL generated by each xenon lamp.

\subsection{Microorganism Counts}

In this study, total mesophilic aerobic bacteria present in the samples before and after IPL were detected. Control and treated samples were aseptically sealed in a sterilized bag after weighing out $10 \mathrm{~g}$ using a spoon that had been sterilized in an autoclave. $\mathrm{NaCl}$ solution $(90 \mathrm{~mL}$ of $0.85 \%)$ was added to each sterilized bag, and homogenization was performed in a shaking incubator (HB-201SF, Hanbaek Scientific, Gwangju, Korea) for $3 \mathrm{~min}$ at $250 \mathrm{rpm}$ and $37^{\circ} \mathrm{C}$. Volumes of $0.1 \mathrm{~mL}$ with serial dilutions with $0.85 \% \mathrm{NaCl}$ of up to $10^{6}: 1$ from the supernatant from the sample mixture were placed on plate count agar (PCA, Difco ${ }^{\mathrm{TM}}$, Sparks, MD, USA) and incubated at $37^{\circ} \mathrm{C}$ for $48-72 \mathrm{~h}$. Colonies formed with 30-300 CFU/mL were counted, and the survival fraction, the ratio of the initial number of microorganisms $\left(N_{\mathrm{o}}\right)$ to the surviving number $(N)$, was measured using Excel 2016 (Microsoft, Redmond, WA, USA).

\subsection{Scanning Electron Microscopy Measurements}

The surface morphologies of the samples were observed using environmental scanning electron microscopy (SL-30FEG, FEI, Burlington, VT, USA) at the Korea Institute of Science and Technology and scanning electron microscopy (TM3030Plus, Hitachi, Tokyo, Japan) at Ewha Womans University.

\subsection{Color Changes}

Colorimetric analyses of treated and control samples were performed using a colorimeter (ColorQuest XE, Hunter Associates Laboratory, Reston, VA, USA), with all measurements replicated three times. The color difference $(\Delta E)$ between untreated and treated samples was analyzed using the $\mathrm{L}$, a, and $\mathrm{b}$ values as measured by the spectrophotometer and applying the following equation:

$$
\Delta E=\sqrt{ }\left((\Delta L)^{2}+(\Delta a)^{2}+(\Delta b)^{2}\right)
$$

\subsection{Changes in Water Activity and Moisture Content}

Changes in the water activities of the treated and control samples were analyzed using a water activity analyzer (AquaLab LITE, Decagon Devices, Pullman, WA, USA). Changes in the moisture contents of the treated and control samples were analyzed using an IR water content analyzer (FD-660, Kett Electric Laboratory, Tokyo, Japan). All measurements were replicated three times. 


\section{Results}

\subsection{Inactivation Effect of IPL Treatment on Seeds and Powdered Foods}

The changes observed in the total microorganisms after treating the four sample types using the developed pilot-scale IPL device are shown in Figure 3.

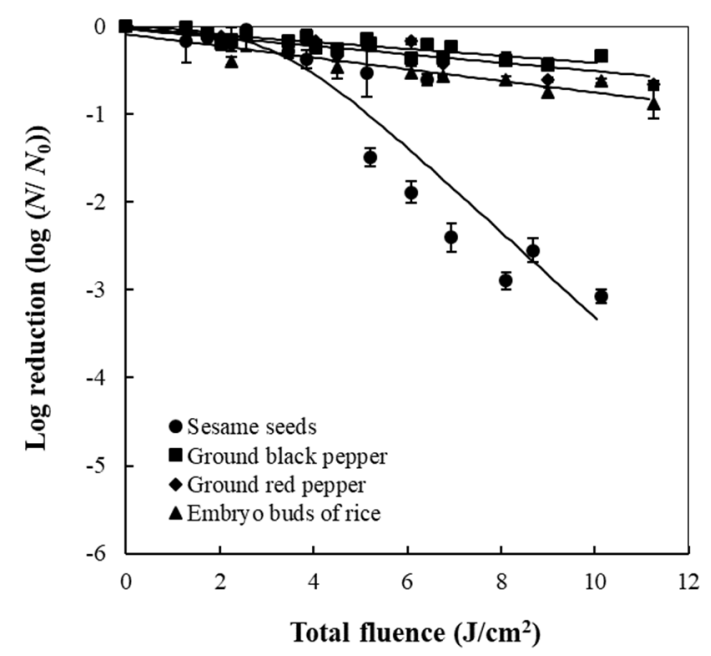

Figure 3. Microbial inactivation effects after IPL treatment of sesame seeds, ground black pepper, ground red pepper, and embryo buds of rice. Data are mean and SEM values.

Sesame seed samples showed the greatest inactivation, with a 3.07-log reduction, while ground black pepper, ground red pepper, and embryo buds of rice showed $0.45-, 0.66-$, and $0.88-\log$ reductions, respectively. The maximum reduction effect varied with the sample type, but the tendency for the inactivation level to improve with increasing treatment time and lamp voltage was the same for all four samples. Since only relatively small reductions have been reported in the literature for powdered foods, many experiments have employed thermal sterilization methods [14-16]. There are some studies on nonheating treatment using UV-C. Of course, the effect of reducing microorganisms was significantly low despite the large amount of energy used. Cheon et al. [14] observed that the reduction in microorganisms on powdered red pepper after exposure to UV-C light at $20.4 \mathrm{~kJ} / \mathrm{m}^{2}$ was $0.22-0.29 \log \mathrm{CFU} / \mathrm{g}$. Adhikari et al. [17] achieved a 2-log reduction of microorganisms on raspberries when applying UV-C light at $11.9 \mathrm{~kJ} / \mathrm{m}^{2}$. However, many previous studies did not investigate temperature increases. Ozer and Demirci [18] studied the inactivation effects of pulsed UV light against two types of bacteria (E. coli O157:H7 and Listeria monocytogenes) inoculated on raw salmon-fillet skin and muscle for various treatment times and distances between a UV light strobe and samples. In all treatments, the temperature of the salmon fillet increased to $100{ }^{\circ} \mathrm{C}$. Similarly, Jun et al. [19] observed temperature increases to $120^{\circ} \mathrm{C}$ when measuring the inactivation effect of pulsed UV light against Aspergillus niger inoculated on cornmeal. Since the above two studies involved laboratory-scale experiments using small samples, they did not monitor for extreme temperature increases. However, adding an efficient cooling system and setting a limit for any temperature increase should be considered when using a pilot-scale device for food-industry applications, since otherwise, it is difficult to distinguish whether microbial inactivation is due to the thermal effect or the direct effects of IPL.

In contrast, the IPL device used in the present study reduced microorganisms on sesame seeds by more than 3-log CFU/g when applying a total fluence of only $11.26 \mathrm{~J} / \mathrm{cm}^{2}$. In addition, the temperature of the samples did not exceed $3.1{ }^{\circ} \mathrm{C}$ during the IPL treatment due to the chilling system mentioned above. Since there are no studies that have achieved more than 3-log microbial reduction effects by processing a large amount of powdery food, the IPL device used in this study showed the high possibility for application in the food industry as a nonthermal processing technology. However, the changes for ground 
black pepper, ground red pepper, and embryo buds of rice did not exceed 1-log reductions, with the effect being slightly better for ground red pepper and embryo buds of rice than for ground black pepper. These results are explained below from both macroscopic and microscopic viewpoints.

\subsection{Effects of Macroscopic Factors on Inactivation}

The four samples used in the study had different surface morphologies after the grinding pretreatment. The sesame seeds did not receive any other pretreatments such as roasting or dulling and exhibited relatively smooth surfaces. Figure $4 \mathrm{~A}$ shows that although pores with sizes of around $20 \mu \mathrm{m}$ were evident, these holes were clogged. In contrast, the ground black pepper, ground red pepper, and embryo buds of rice had been ground by a blender or thresher, and so their surfaces contained many cracks and were very rough (Figure $4 \mathrm{~B}-\mathrm{D}$ ). The microbial reduction of ground black pepper was remarkably low among these three samples, and its surface also looked distinctively like coral. Woodling and Moraru [20] studied the influence of surface morphology on the efficacy of pulsed light treatment and reported that greater surface roughness increased the probability of microbial cells hiding within surface features. However, they inoculated L. innocua onto four types of stainless-steel surfaces, and the uniformity of the spreading of the inoculum was another variable influencing the effect of pulsed light. In this study, the ground samples were presented with crevices and cracks on their surfaces, which offered places where bacteria could harbor; previous studies have defined this phenomenon as a shadow effect [21].

The color of samples could be another factor affecting the efficacy of IPL. It was visually apparent that the ground black pepper and sesame seeds were the darkest and brightest samples, respectively. Previous studies have shown that inactivation effects may be reduced for darker samples due to their greater absorption of UV light [7,22]. The effects of pulsed light on color differences of bacteria and fungi and the pigments synthesized by them have also been examined [23-25]. Pseudomonas fluorescens, a Gram-negative strain, can synthesize the blue, fluorescent pigment called pyoverdin, which can absorb UV light and reduce the effects of pulsed light. Turtoi and Nicolau also confirmed that dark-colored phialospores produced by A. niger (black) and A. cinnamomeus (brown) were more easily destroyed than $A$. repens, which has a green color. The study of Esbelin et al. [23] compared the effects of pulsed light and monochromatic $(254 \mathrm{~nm})$ UV-C light in three A. niger strains with the same genetic background. Those authors found that samples with light tan and white pigments were more sensitive to pulsed light and continuous UV-C absorption than the wild-type and dark samples. Moreover, the mutant and dark A. niger mutants were similarly resistant to moist heat at $56^{\circ} \mathrm{C}$, while white spores reacted very sensitively, confirming that melanin protected pigmented spores from IPL.

\subsection{Effects of Microscopic Factors on Inactivation}

The microscopic viewpoint addresses different types of natural microflora in the samples. Microbial inactivation mechanisms caused by IPL are mainly attributable to DNA damage. First of all, microorganisms have different susceptibilities to light due to their inherent characteristics. In particular, spores have much higher resistances than vegetative cells due to their thick outer and inner coats being made of protein and having a peptidoglycan cortex [26,27]. Our analysis of the natural microorganisms associated with the ground black pepper, which exhibited the lowest inactivation effect after IPL treatment, showed that $27 \%$ were Bacillus spp., most of which were high-resistance spores (data not shown). 


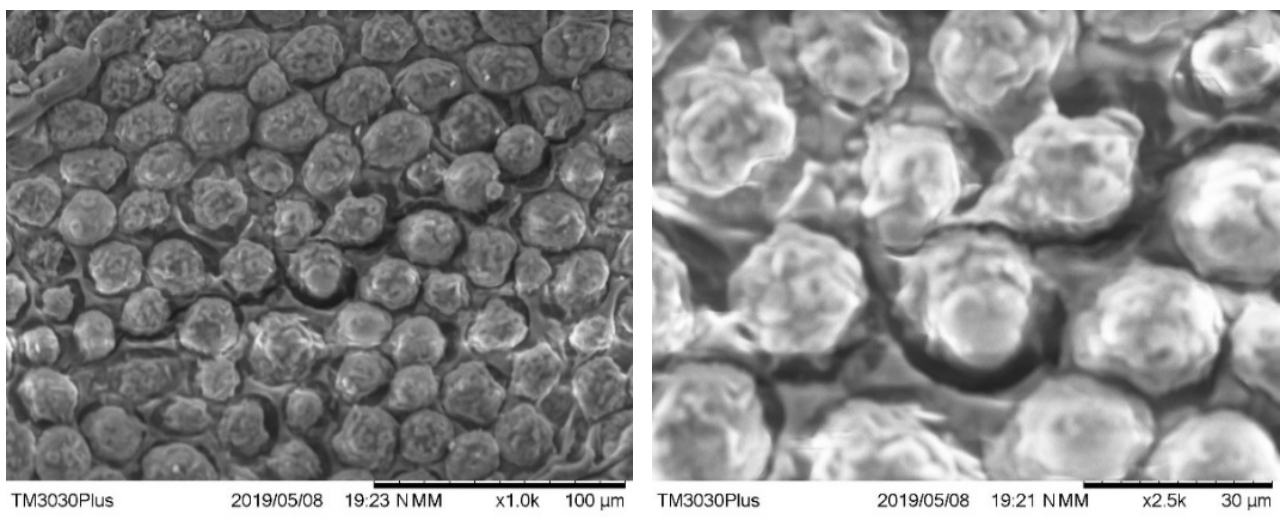

(A)
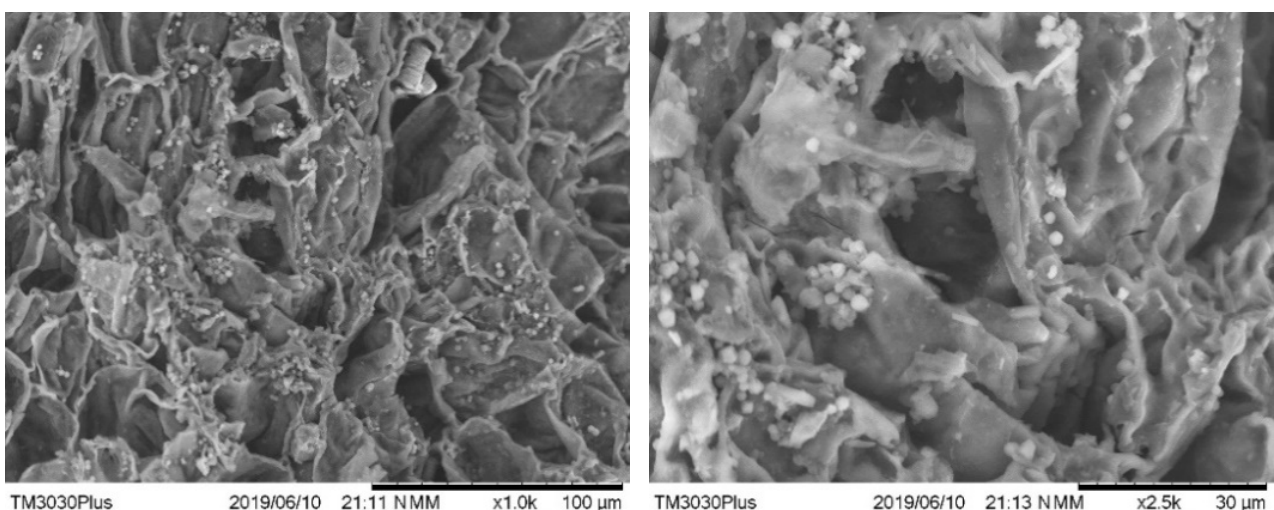

(B)
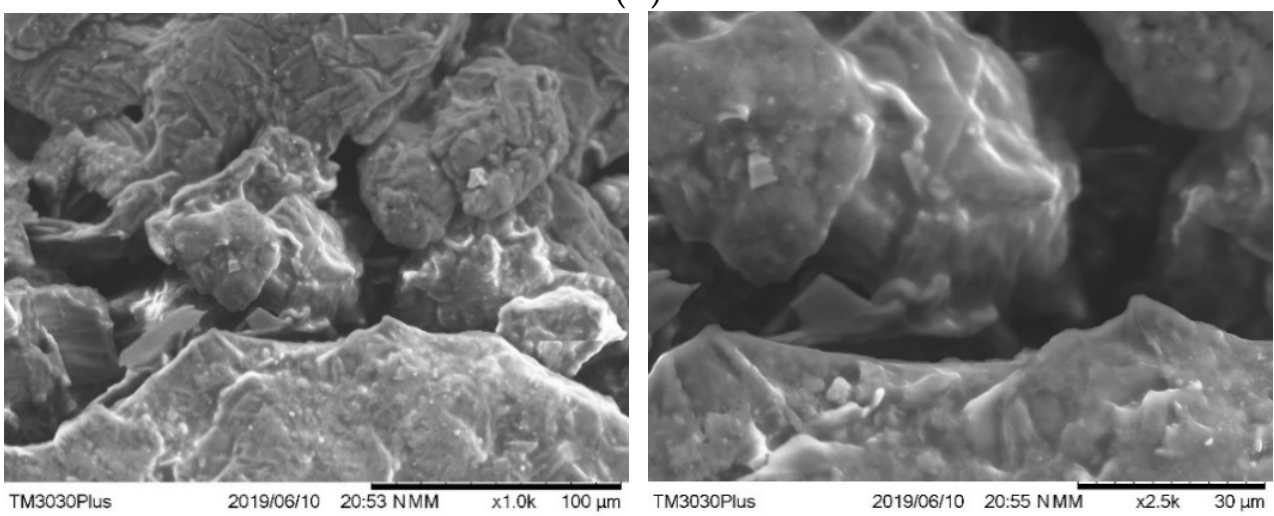

(C)
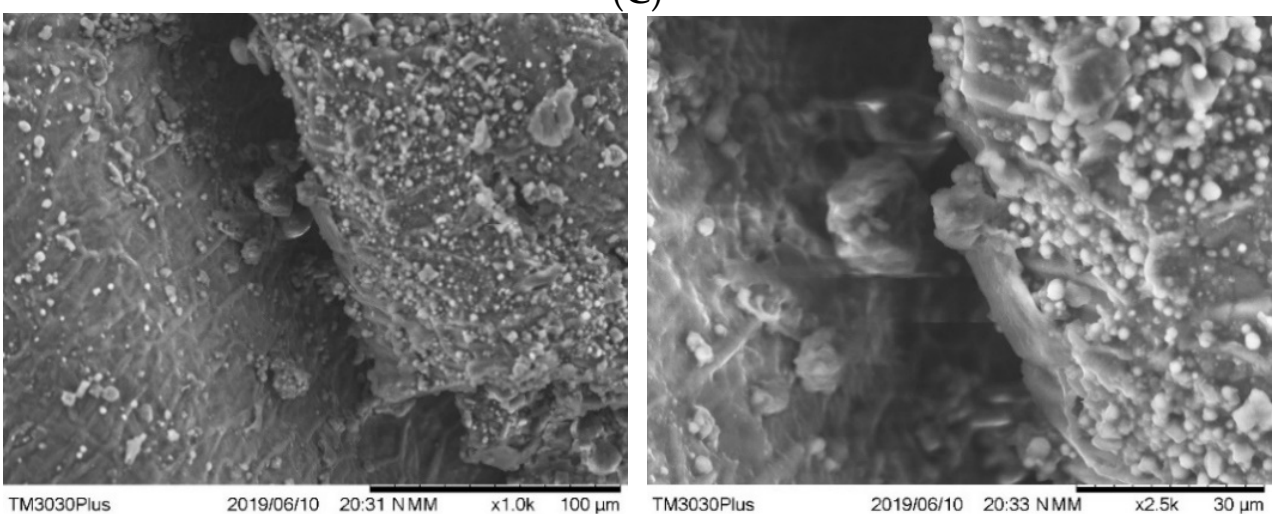

(D)

Figure 4. Scanning electron microscopy images of (A) sesame seeds, (B) ground black pepper, (C) ground red pepper, and (D) embryo buds of rice. 
On the other hand, the proportion of Bacillus subtilis vegetative cells and molds was relatively high in sesame seeds, which induced a strong inactivation effect. Many previous studies have confirmed the highly destructive effects of pulsed light on vegetative cells of B. subtilis, because they are more sensitive to external stimuli than are spores [28-30]. Nicorescu et al. [30] measured the IPL-induced inactivation effects and cell integrity of artificially inoculated B. subtilis vegetative cells in a liquid state and spices (ground caraway, ground red pepper, and ground black pepper). In the liquid state, an 8-log reduction of B. subtilis cells was observed after only a single flash of pulsed light $\left(0.6 \mathrm{~J} / \mathrm{cm}^{2}\right)$. In contrast, $10 \mathrm{~J} / \mathrm{cm}^{2}$ was needed to produce an inactivation of approximately $1 \log$ for cells inoculated in spices. The results in Figure 3 similarly show that dry samples showed less inactivation than liquid samples, but the potential for their inactivation has still been demonstrated. The effect of IPL on vegetative cells and spores of B. subtilis was compared in the study of Artíguez and de Marañón [28], who found that both microbial counts decreased as the total fluence increased. Spores are obviously more resistant than vegetative cells, with Bacillus spores exhibiting 3-log reductions but 5-log reductions being achieved for vegetative cells at $10^{7}$ cells $/ \mathrm{mL}$ and a total fluence of $0.5 \mathrm{~J} / \mathrm{cm}^{2}$.

\subsection{Measuring Changes in Physical Properties}

One critical advantage of employing a nonthermal sterilization method is reducing the deterioration of the physical and sensory properties in food samples by minimizing the temperature increase [31]. Therefore, the microbial inactivation effect is not the only factor that should be considered. First, the differences in the spectrophotometer results before and after treatment are listed in Table 1 . The strongest treatment condition was $4200 \mathrm{~V}$ for $5 \mathrm{~min}$, while the lamp was not turned on for the control sample. $\Delta E$ values can be classified as not noticeable (0-0.5) and slightly noticeable (0.5-1.5) [32], and applying these criteria indicates that none of the four treated samples differed significantly from the control sample. The physical change of a sample (including its color) can be considered a very important indicator because it can reflect sensory differences.

Table 1. Color difference of samples before and after IPL treatment at $4200 \mathrm{~V}$ for $5 \mathrm{~min}$. Data are mean \pm standard deviation (SD) values.

\begin{tabular}{|c|c|c|c|c|c|c|c|}
\hline & \multicolumn{3}{|c|}{ Control } & \multicolumn{3}{|c|}{ After IPL Treatment } & \multirow{2}{*}{$\Delta E$} \\
\hline & $\mathbf{L}$ & a & $\mathbf{b}$ & $\mathbf{L}$ & a & $\mathbf{b}$ & \\
\hline Sesame seeds & $57.78 \pm 0.21$ & $4.68 \pm 0.06$ & $17.3 \pm 0.12$ & $57.34 \pm 0.21$ & $4.03 \pm 0.26$ & $17.22 \pm 0.30$ & 0.79 \\
\hline Ground black pepper & $41.00 \pm 0.18$ & $3.44 \pm 0.08$ & $14.14 \pm 0.09$ & $42.19 \pm 0.62$ & $3.03 \pm 0.21$ & $13.58 \pm 0.49$ & 1.38 \\
\hline Ground red pepper & $28.54 \pm 0.50$ & $29.17 \pm 0.11$ & $23.04 \pm 0.08$ & $29.57 \pm 0.52$ & $28.61 \pm 0.26$ & $22.06 \pm 0.04$ & 1.53 \\
\hline Embryo buds of rice & $63.52 \pm 0.31$ & $4.25 \pm 0.09$ & $23.95 \pm 0.03$ & $62.43 \pm 0.18$ & $4.21 \pm 0.08$ & $24.55 \pm 0.402$ & 1.26 \\
\hline
\end{tabular}

The differences in water content and water activity before and after treatment at $4200 \mathrm{~V}$ for $5 \mathrm{~min}$ are presented in Table 2. There were almost no significant differences in these two characteristics before and after the treatment. Hwang et al. [33] similarly found no significant changes in water activity or moisture content in other types of seeds such as cassia seeds and glutinous millet. Not just in color and water properties: appropriate IPL treatment does not affect food taste, flavor, or odor, either. Tomašević [34] mentioned that IPL treatment of $3.4 \mathrm{~J} / \mathrm{cm}^{2}$ did not change the appearance or total taste and odor scores of beef. Hierro et al. [35] also observed no change in color, flavor, appearance, or odor in ham treated with IPL up to $3.4 \mathrm{~J} / \mathrm{cm}^{2}$. In conclusion, it is identified that IPL does not affect the physical properties of these powdery samples. It reveals the potential of this IPL device to be applied to the practical food industry and offers a prospect for developing IPL systems that can handle large amounts of powdery foods. 
Table 2. Measured water content and water activity of samples after IPL treatment. Data are mean \pm SEM values.

\begin{tabular}{ccccc}
\hline & \multicolumn{2}{c}{ Water Content (\%) } & \multicolumn{2}{c}{ Water Activity } \\
\cline { 2 - 5 } & Control & Treated & Control & Treated \\
\hline Sesame seeds & $5.12 \pm 0.21^{\mathrm{a}}$ & $5.11 \pm 0.10^{\mathrm{a}}$ & $0.36 \pm 0.01^{\mathrm{a}}$ & $0.32 \pm 0.01^{\mathrm{a}}$ \\
Ground black pepper & $11.23 \pm 0.19^{\mathrm{a}}$ & $10.62 \pm 0.30^{\mathrm{a}}$ & $0.35 \pm 0.05^{\mathrm{a}}$ & $0.28 \pm 0.05^{\mathrm{ab}}$ \\
Ground red pepper & $13.34 \pm 0.35^{\mathrm{a}}$ & $12.82 \pm 0.15^{\mathrm{ab}}$ & $0.35 \pm 0.00^{\mathrm{a}}$ & $0.34 \pm 0.01^{\mathrm{ab}}$ \\
Embryo buds of rice & $8.34 \pm 0.21^{\mathrm{a}}$ & $8.03 \pm 0.15^{\mathrm{a}}$ & $0.35 \pm 0.01^{\mathrm{a}}$ & $0.34 \pm 0.00^{\mathrm{a}}$ \\
\hline
\end{tabular}

$\mathrm{a}, \mathrm{b}$, within a column, different letters within indicate significantly different value $(p \leq 0.05)$.

\section{Discussion}

This study developed a sterilization device for seeds and powdered foods based on IPL and consisting of two power supplies, two xenon lamps, and a treatment chamber. The device was designed to allow samples to receive as much light as possible for as long as possible in order to increase its effectiveness. The sample flows through the device in a cyclonic manner, which allows the sample to remain in the chamber for longer than if it simply fell straight through and also is less likely to be present in clumps. Each of the two power supplies was set at $1800-4200 \mathrm{~V}$ for 1-5 min in the experiments performed in this study. The resulting microbial inactivation effects for sesame seeds, embryo buds of rice, ground red pepper, and ground black pepper decreased in the order of 3.07-, 0.88-, 0.66-, and $0.45-\log$ reductions, respectively. These results can be explained by considering both macroscopic and microscopic differences between the samples. First, from a macroscopic viewpoint, the morphologies of sample surfaces vary depending on whether or not they have been ground, and the presence of irregular cracks would result in shadow effects and associated reductions in microbial inactivation. Additionally, the inactivation effect will be lower for darker samples due to less absorption of the incident UV light. Second, from a microscopic viewpoint, the natural microflora present differed between the samples. The inactivation effect was lower for samples harboring low-susceptibility spores since they are more resistant than vegetative cells and molds. In addition to microbiological changes, physical changes that may affect sensory properties are also important to consider. The present statistical analyses revealed that there were no significant changes in color, water activity, or moisture content in the four samples. In conclusion, this study showed that the present pilot-scale IPL device for processing seeds and powdered foods is capable of handling large amounts of samples daily. It is highly significant that no changes were observed in the basic properties of food after IPL because it means that IPL can fully compensate for the disadvantages of heat sterilization. It is expected that this study will contribute to the commercialization of IPL technology, and further studies for developing a device that combines other nonthermal techniques for applying to spices, other seeds, and powdered foods contaminated by microorganisms need to be conducted.

Author Contributions: Conceptualization, H.-J.H. and S.-Y.Y.; methodology, S.-Y.Y.; software, S.-Y.Y.; validation, H.-J.H. and S.-Y.Y.; formal analysis, S.-Y.Y.; investigation, S.-Y.Y.; resources, S.-Y.Y.; data curation, H.-J.H.; writing—original draft preparation, S.-Y.Y;; writing—review and editing, H.-J.H.; visualization, H.-J.H.; supervision, M.-S.C.; project administration, M.-S.C. All authors have read and agreed to the published version of the manuscript.

Funding: This research received no external funding.

Institutional Review Board Statement: Not applicable.

Informed Consent Statement: Not applicable.

Data Availability Statement: The data presented in this study are available on request from the corresponding author.

Acknowledgments: This work was supported by the Basic Science Research Program through the National Research Foundation of Korea (NRF) funded by the Ministry of Education (NRF2019R1A2C1085100). 
Conflicts of Interest: The authors declare no conflict of interest.

\section{References}

1. Karsha, P.V.; Lakshmi, O.B. Antibacterial activity of black pepper (Piper nigrum Linn.) with special reference to its mode of action on bacteria. Indian J. Nat. Prod. Resour. 2010, 1, 213-215.

2. Kim, S.T.; Wang, Y.; Kang, S.Y.; Kim, S.G.; Rakwal, R.; Kim, Y.C.; Kang, K.Y. Developing rice embryo proteomics reveals essential role for embryonic proteins in regulation of seed germination. J. Proteome Res. 2009, 8, 3598-3605. [CrossRef]

3. [USFDA] Food and Drug Administration. Enforcement report. Recalls and Field Corrections: Foods-Class I; Recall Number F-535-1; USFDA: Silver Spring, MD, USA, 2001.

4. Banerjee, M.; Sarkar, P.K. Microbiological quality of some retail spices in India. Food Res. Int. 2003, 36, 469-474. [CrossRef]

5. Rendlen, M. Hygienic problems of phytogenic raw materials for food production with special emphasis to herbs and spices. Food Sci. Biotechnol. 2004, 13, 262-268.

6. Oularbi, S.; Mansouri, B. Decontamination of black pepper and red pepper by gamma radiation. Radiat. Phys. Chem. 1996, $48,386$. [CrossRef]

7. Fine, F.; Gervais, P. Efficiency of pulsed UV light for microbial decontamination of food powders. J. Food Prot. 2004, 67, 787-792. [CrossRef] [PubMed]

8. Almela, L.; Nieto-Sandoval, J.M.; Fernández López, J.A. Microbial inactivation of paprika by a high-temperature short-X time treatment. Influence on color properties. J. Agric. Food. Chem. 2002, 50, 1435-1440. [CrossRef] [PubMed]

9. Bhavya, M.L.; Umesh Hebbar, H. Pulsed light processing of foods for microbial safety. Food Qual. Saf. 2017, 1, 187-202. [CrossRef]

10. Agüero, M.V.; Jagus, R.J.; Martín-Belloso, O.; Soliva-Fortuny, R. Surface decontamination of spinach by intense pulsed light treatments: Impact on quality attributes. Postharvest Biol. Technol. 2016, 121, 118-125. [CrossRef]

11. Gómez-López, V.M.; Devlieghere, F.; Bonduelle, V.; Debevere, J. Factors affecting the inactivation of micro-organisms by intense light pulses. J. Appl. Microbiol. 2005, 99, 460-470. [CrossRef] [PubMed]

12. Roberts, P.; Hope, A. Virus inactivation by high intensity broad spectrum pulsed light. J. Virol. Methods. 2003, 110, 61-65. [CrossRef]

13. Wekhof, A. Disinfection with flash lamps. PDA J. Pharm. Sci. Technol. 2000, 54, 264-276.

14. Cheon, H.L.; Shin, J.Y.; Park, K.H.; Chung, M.S.; Kang, D.H. Inactivation of foodborne pathogens in powdered red pepper (Capsicum annuиm L.) using combined UV-C irradiation and mild heat treatment. Food Control 2015, 50, 441-445. [CrossRef]

15. Fine, F.; Gervais, P. A new high temperature short time process for microbial decontamination of seeds and food powders. Powder Technol. 2005, 157, 108-113. [CrossRef]

16. Hu, S.; Zhao, Y.; Hayouka, Z.; Wang, D.; Jiao, S. Inactivation kinetics for Salmonella typhimurium in red pepper powders treated by radio frequency heating. Food Control 2018, 85, 437-442. [CrossRef]

17. Adhikari, A.; Syamaladevi, R.M.; Killinger, K.; Sablani, S.S. Ultraviolet-C light inactivation of Escherichia coli O157:H7 and Listeria monocytogenes on organic fruit surfaces. Int. J. Food Microbiol. 2015, 210, 136-142. [CrossRef] [PubMed]

18. Ozer, N.P.; Demirci, A. Inactivation of Escherichia coli O157:H7 and Listeria monocytogenes inoculated on raw salmon fillets by pulsed UV-light treatment. Int. J. Food. Sci. Tech. 2006, 41, 354-360. [CrossRef]

19. Jun, S.; Irudayaraj, J.; Demirci, A.; Geiser, D. Pulsed UV-light treatment of corn meal for inactivation of Aspergillus niger spores. Int. J. Food. Sci. Tech. 2003, 38, 883-888. [CrossRef]

20. Woodling, S.E.; Moraru, C.I. Influence of surface topography on the effectiveness of pulsed light treatment for the inactivation of Listeria innocua on stainless-steel surfaces. J. Food Sci. 2005, 70, m345-m351. [CrossRef]

21. Condón-Abanto, S.; Condón, S.; Raso, J.; Lyng, J.G.; Álvarez, I. Inactivation of Salmonella typhimurium and Lactobacillus plantarum by UV-C light in flour powder. Innov. Food Sci. Emerg. Technol. 2016, 35, 1-8. [CrossRef]

22. Hong, H.J.; Kim, A.J.; Park, H.R.; Shin, J.K. Changes in physicochemical properties of paprika by intense pulsed light treatment. Korean J. Food Sci. Technol. 2013, 45, 339-344. [CrossRef]

23. Esbelin, J.; Mallea, S.; Ram, A.F.; Carlin, F. Role of pigmentation in protecting Aspergillus niger conidiospores against pulsed light radiation. Photochem. Photobiol. 2013, 89, 758-761. [CrossRef] [PubMed]

24. Proulx, J.; Hsu, L.C.; Miller, B.M.; Sullivan, G.; Paradis, K.; Moraru, C.I. Pulsed-light inactivation of pathogenic and spoilage bacteria on cheese surface. J. Dairy Sci. 2015, 98, 5890-5898. [CrossRef]

25. Turtoi, M.; Nicolau, A. Intense light pulse treatment as alternative method for mould spores destruction on paper-polyethylene packaging material. J. Food Eng. 2007, 83, 47-53. [CrossRef]

26. Driks, A. Maximum shields: The assembly and function of the bacterial spore coat. Trends Microbiol. 2002, 10, 251-254. [CrossRef]

27. Melly, E.; Genest, P.; Gilmore, M.E.; Little, S.; Popham, D.L.; Driks, A.; Setlow, P. Analysis of the properties of spores of Bacillus subtilis prepared at different temperatures. J. Appl. Microbiol. 2002, 92, 1105-1115. [CrossRef]

28. Artíguez, M.L.; de Marañón, I.M. Inactivation of spores and vegetative cells of Bacillus subtilis and Geobacillus stearothermophilus by pulsed light. Innov. Food Sci. Emerg. Technol. 2015, 28, 52-58. [CrossRef]

29. Levy, C.; Aubert, X.; Lacour, B.; Carlin, F. Relevant factors affecting microbial surface decontamination by pulsed light. Int. J. Food Microbiol. 2012, 152, 168-174. [CrossRef] [PubMed]

30. Nicorescu, I.; Nguyen, B.; Moreau-Ferret, M.; Agoulon, A.; Chevalier, S.; Orange, N. Pulsed light inactivation of Bacillus subtilis vegetative cells in suspensions and spices. Food Control 2013, 31, 151-157. [CrossRef] 
31. Elmnasser, N.; Guillou, S.; Leroi, F.; Orange, N.; Bakhrouf, A.; Federighi, M. Pulsed-light system as a novel food decontamination technology: A review. Can. J. Microbiol. 2007, 53, 813-821. [CrossRef] [PubMed]

32. Cserhalmi, Z.; Sass-Kiss, A.; Tóth-Markus, M.; Lechner, N. Study of pulsed electric field treated citrus juices. Innov. Food Sci. Emerg. Technol. 2006, 7, 49-54. [CrossRef]

33. Hwang, H.J.; Cheigh, C.I.; Chung, M.S. Comparison of bactericidal effects of two types of pilot-scale intense-pulsed-light devices on cassia seeds and glutinous millet. Innov. Food Sci. Emerg. Technol. 2018, 49, 170-175. [CrossRef]

34. Tomašević, I. The effect of intense light pulses on the sensory quality and instrumental color of meat from different animal breeds. Biotech. Anim. Husb. 2015, 31, 273-281. [CrossRef]

35. Hierro, E.; Barroso, E.; De la Hoz, L.; Ordóñez, J.A.; Manzano, S.; Fernández, M. Efficacy of pulsed light for shelf-life extension and inactivation of Listeria monocytogenes on ready-to-eat cooked meat products. Innov. Food Sci. Emerg. Technol. 2011, 12, 275-281. [CrossRef] 